\title{
A COMPARATIVE STUDY OF THE CHARACTERISTICS OF SUICIDAL IDEATIONS AND ATTEMPTS BETWEEN PATIENTS WITH SCHIZOPHRENIA AND BIPOLAR DISORDERS
}

\author{
Nileena Namboodiripad Kakkattu Mana ${ }^{1}$, R. Saravana Jothi'2, Alexander Gnana Durai ${ }^{3}$, Sree Kumar E. J4, \\ M. Mohammed Ilyas Rahamathulla 5 , P. Hariharan ${ }^{6}$, D. Punithavatad 7 , R. Priya Darsdhini ${ }^{8}$ \\ ${ }_{1}^{1}$ Junior Resident, Department of Psychiatry, Stanley Medical College, Chennai. \\ ${ }^{2}$ Associate Professor, Department of Psychiatry, Stanley Medical College, Chennai. \\ ${ }^{3}$ Professor, Department of Psychiatry, Stanley Medical College, Chennai. \\ ${ }^{4}$ Assistant Professor (Statistician), Department of Anaesthesia, SRMC, Chennai. \\ ${ }^{5}$ Assistant Professor, Department of Psychiatry, Stanley Medical College, Chennai. \\ ${ }^{6}$ Assistant Professor, Department of Psychiatry, Stanley Medical College, Chennai. \\ 7 Junior Resident, Department of Psychiatry, Stanley Medical College, Chennai. \\ 8 Junior Resident, Department of Psychiatry, Stanley Medical College, Chennai.
}

ABSTRACT

\section{BACKGROUND}

Suicide in psychiatric illnesses is mostly seen in mood disorders followed by schizophrenia. This study is an attempt to compare the risk factors associated with suicide in bipolar affective disorder and schizophrenia.

\section{MATERIALS AND METHODS}

The study was a descriptive comparative study. Thirty patients with schizophrenia and thirty patients with bipolar affective disorder with suicidal ideation and/or suicidal attempts were analysed for their socio-demographic and illness characteristics.

\section{RESULTS}

All the patients had suicidal ideations and there were 16 suicide attempters. There were more illiterates with bipolar disorder. The younger bipolar patients tended to have higher scores for suicidal ideation and intent. The suicidal ideation increased with the level of education $(\mathrm{p}=0.027)$. All patients had depression. All suicidal attempts were associated with severe suicidal ideation. The severity of suicidal ideation increased with the number of previous attempts.

\section{CONCLUSION}

This study justifies the need for regular followup and screening for suicidal ideations in both schizophrenia and bipolar disorders considering the aforementioned factors.

\section{KEYWORDS}

Suicidal Ideation, Suicidal Attempt, Schizophrenia, Bipolar Disorders.

HOW TO CITE THIS ARTICLE: Mana NNK, Jothi RS, Durai AG, et al. A comparative study of the characteristics of suicidal ideations and attempts between patients with schizophrenia and bipolar disorders. J. Evolution Med. Dent. Sci. 2017;6(61):4478-4482, DOI: $10.14260 /$ Jemds/2017/968

\section{BACKGROUND}

Psychiatric illnesses form a significant portion of the global disease burden. Suicide or the act of taking one's own life is one of the major complications of psychiatric illnesses. Seventy-five percent of the suicidal deaths occur in the low and middle-income countries, which includes India.(1) For every suicidal death, there is 25 times the number of suicidal attempts.(2) Approximately $95 \%$ of all individuals who commit or attempt suicide have a psychiatric diagnosis.(2) Of the various mood disorders, depression is most frequently associated with suicide. Untreated depression has a lifetime risk of suicide from $2.2 \%$ to $15 \%$. Mania, though rare has also been shown to lead to increased suicide risk.

Financial or Other, Competing Interest: None.

Submission 24-06-2017, Peer Review 18-07-2017,

Acceptance 24-07-2017, Published 31-07-2017.

Corresponding Author:

R. Saravana Jothi,

Associate Professor,

Department of Psychiatry,

Stanley Medical College,

Chennai.

E-mail: saravanajothi@gmail.com

DOI: $10.14260 /$ jemds $/ 2017 / 968$

\section{(c) $($ ) $\$$}

Male gender, family history of suicide, suicidal ideation, psychotic symptoms, former suicide attempts, hopelessness, comorbid personality disorders, substance use and anxiety disorders have been found to be contributing determinants towards completed suicide in many prospective cohort studies.(3) In people with schizophrenia, it has been demonstrated that there is a suicide risk of $5 \%$.(4) Risk factors in schizophrenia include early onset of disease, male gender, unemployed, higher levels of education, rural, comorbid physical illness, depression, positive symptoms and presence of insight.

In a retrospective study by Takao Ishii et al,(5) comparison of the characteristics of suicide attempters among schizophrenics and those with unipolar and bipolar mood disorders found differing characteristics among the groups in relation to their age, comorbidities, severity of attempt and treatment interruption. The study did not include patients with suicidal ideations and included patients with both unipolar and bipolar mood disorder. This study focused on the patients diagnosed with schizophrenia and bipolar disorder harbouring suicidal ideations and/or attempts in the Indian population. The study also tried to seek an association between suicide attempt and mania, for which much literature is not available. 


\section{MATERIALS AND METHODS \\ Study Population}

After obtaining Institutional Ethical Committee clearance, the sample was drawn from patients attending the Psychiatry Department at Government Stanley Medical College and Hospital, Chennai.

\section{Inclusion Criteria}

- Patients with schizophrenia and bipolar affective disorder, satisfying the criteria for the corresponding DSM-V diagnosis with suicidal ideation and/or history of suicidal attempt within past one month.

- Patients of either sex belonging to the age group 18 - 60 years.

\section{Exclusion Criteria}

- Legal guardian or patient refusal.

- Patients with schizoaffective disorder meeting the criteria for the corresponding DSM-V diagnosis.

- Patients with substance abuse meeting the criteria of dependence.

- Patients with any chronic physical illness and on treatment for the same.

\section{Study Design}

The study was a descriptive comparative study, evaluating 30 patients with schizophrenia and 30 patients with bipolar affective disorder. The duration of the study was 6 months. It was a sample of convenience based on the number of cases seen in the previous 6 months in the department.

\section{Assessment Procedure of the Study}

Detailed socio-demographic details (Age, sex, education, religion, socio-economic status, etc.) and illness details (Period of illness, length of treatment, substance abuse, sum of suicidal ideation, sum of suicidal attempts, ICU admissions, etc.) were recorded in the semi-structured proforma sheet designed for this study. To measure the specific variables, the following scales were used in the study-

1. Presumptive Stressful Life Events Scale (PSLES)- The scale is an Indian version of the Holmes and Rahe's Social Readjustment Rating Schedule constructed by Gurmeet Singh in 1984.(6) It contains a number of possible life events experienced by a common man as well as the presumptive stress score for each event for this population. It can range from 0 - 100.(6)

2. Modified Scale for Suicidal Ideation (MSSI)- It is a clinician rated measure of suicidal ideations with 18 items from the original version, of which 5 are new items. The MSSI evaluates the suicidal symptoms present anytime in the past one year. The initial four items serve as a screening to warrant the necessity of using the entire scale.(7)

3. Beck's Suicide Intent Scale (BSI)- It collects information regarding the suicidal attempt and applies it to assess how serious the attempt was. The scale helps in analysing consequent suicidal risk.(8) This scale was administered on those who had attempted suicide.

4. Brief Psychiatric Rating Scale (BPRS)- The scale measures mainly the severity of the psychotic symptoms and was given to all patients with schizophrenia. The 18item version was used.(9)
5. Calgary Depression Scale For Schizophrenia (CDSS)Addington et al had developed the Calgary depression scale for schizophrenia in 1990 to assess depressive symptoms distinct from the positive, negative and even extrapyramidal symptoms in people with schizophrenia. It is an observer scale, semi-structured, goal-directed interview and has nine items. ${ }^{(10)}$

6. Hamilton Depression Rating Scale (HAM-D)Hamilton Depression Rating Scale (HDRS), also identified as HAM-D is a multiple item questionnaire used to provide a severity assessment of depression and is used to monitor progress along the course of illness. The original 1960 version contained 17 items. In this study, the 21 item version was used.(11)

7. Clinician Administered Rating Scale for Mania (CARSM)- The scale has a total of 15 items. It has two subscales: One for the manic symptoms and another for the psychotic symptoms. ${ }^{(12)}$

\section{Statistical Analysis}

Statistical analysis was done using SPSS trial version 24 Binary variables were analysed by $\mathrm{X}^{2}$ test. Ordinal variables was analysed by Kendall's tau test. Nominal variables were analysed by Phi test. Non-parametric tests were analysed by Fisher's exact for binary. For continuous data which followed non-parametric distribution, Kruskal-Wallis test was used? For multiple measurements, Bon Ferroni correction was applied.

\section{RESULTS}

A descriptive comparative study was executed to compare the characteristics of suicidal ideations and attempts between patients with schizophrenia and bipolar disorders. Each group had 30 patients. There was a significant difference in education $(\mathrm{p}=0.036)$ (Table 1$)$. There were 7 illiterates in bipolar disorder patients group, while there was nobody illiterate in the schizophrenia group. No other sociodemographic factors showed any significant difference in distribution.

The total PSLES scores were found to be significantly different between patients sorrowed with schizophrenia when compared to those with bipolar disorder, though statistical significance was not observed when PSLES scores were grouped by severity. Mean observed scores were 99.93 \pm 28.627 and $79.27 \pm 36.26$ in schizophrenia and bipolar disorder respectively (Table 2). The ' $\mathrm{P}$ ' value obtained was 0.017. The mean scores in BSI were $31.63 \pm 3.159$ and $28.13 \pm$ 6.707 in schizophrenia and bipolar disorder respectively. There was no significant difference in either group.

The mean ages of patients with bipolar disorder with each grade of severity in MSSI were $43.2 \pm 10.81,39.2 \pm 11.42$ and $34.58 \pm 10.53$. There was also association between education level and suicidal ideation in bipolar disorder (Table 3). People with higher education tended to have stronger suicidal ideation.

Duration of illness and treatment were observed to have an effect on the suicidal ideation severity. The mean duration of illness for both disorders combined considering the severity (low-to-severe) on MSSI were $14.88 \pm 10.21,13.38 \pm$ 8.49 and $8.73 \pm 7.29$ (in years). The relation between suicidal ideation and duration of treatment seems to be significant with 'p' values of 0.014 (Table 4). 
The mean duration for each grade of suicidal ideation (in increasing severity) were $12.52 \pm 9.58,9.92 \pm 8.69$ and $6.64 \pm$ 6.48 (in years). This showed that the younger age group had more severe suicidal ideation. But this association was lost on Bonferroni correction. In bipolar disorder, the association was not lost even with post hoc tests. The suicidal intent when considering both disorders combined does not show any association to any of the socio-demographic profile.

Four components of BPRS came out to be significant. They are depression, suicidality and suspiciousness and disorientation. Higher scores on depression, suicidality and suspiciousness were interconnected with higher scores on MSSI. However, disorientation showed suicidality with lower scores on disorientation. When looking into the suicide intent in bipolar disorder, there is higher suicidal intent in younger individuals. The ' $p$ ' value being 0.028 . Strong association was seen between presence of depression and suicidal ideation. The ' $p$ ' value for overall illness is 0.000 . The ' $p$ ' value for schizophrenia is 0.000 and that for bipolar disorder is 0.0012 showing good association between the two within the groups. All the suicidal attempts had suicidal ideations temporal to the events. There was always severe suicidal ideation before an attempt. Presence of previous suicidal attempts is significantly associated with the severity of suicidal ideations (Table 5). However, this relationship could not be established for suicide intent.

\begin{tabular}{|c|c|c|c|c|}
\hline & & SCZ & BP & P Value \\
\hline \multirow{2}{*}{ Gender } & Male & 14 & 12 & \multirow{2}{*}{0.602} \\
\hline & Female & 16 & 18 & \\
\hline \multicolumn{2}{|c|}{ Age $^{a}$} & $37.53 \pm 8.64$ & $38.57 \pm 11.125$ & 0.689 \\
\hline \multirow{3}{*}{ Religion } & Christian & 4 & 2 & \multirow{3}{*}{0.162} \\
\hline & Hindu & 24 & 21 & \\
\hline & Muslim & 2 & 7 & \\
\hline \multirow{5}{*}{ Education } & Illiterate & $0^{*}$ & $7^{*}$ & \multirow{5}{*}{$0.036^{*}$} \\
\hline & Primary & 8 & 3 & \\
\hline & Secondary & 10 & 12 & \\
\hline & $\begin{array}{c}\text { Higher } \\
\text { Secondary }\end{array}$ & 8 & 5 & \\
\hline & College & 4 & 3 & \\
\hline \multirow{5}{*}{$\begin{array}{l}\text { Marital } \\
\text { Status }\end{array}$} & Single & 4 & 7 & \multirow{5}{*}{0.338} \\
\hline & Married & 25 & 20 & \\
\hline & Separated & 1 & 1 & \\
\hline & Divorced & 0 & 2 & \\
\hline & Widowed & 0 & 0 & \\
\hline \multirow{2}{*}{$\begin{array}{l}\text { Type of } \\
\text { Family }\end{array}$} & Nuclear & 21 & 18 & \multirow{2}{*}{0.417} \\
\hline & Joint & 9 & 12 & \\
\hline \multicolumn{2}{|c|}{ Number of Caregivers $\mathrm{a}$} & $1.73 \pm 0.785$ & $1.93 \pm 0.785$ & 0.328 \\
\hline \multirow{3}{*}{$\begin{array}{c}\text { Socio- } \\
\text { economic } \\
\text { status }\end{array}$} & Low & 22 & 27 & \multirow{3}{*}{0.095} \\
\hline & Moderate & 8 & 3 & \\
\hline & High & 0 & 0 & \\
\hline \multirow{2}{*}{ Locality } & Urban & 17 & 19 & \multirow{2}{*}{0.598} \\
\hline & Rural & 13 & 11 & \\
\hline \multicolumn{5}{|c|}{ Table 1. Sociodemographic Profile } \\
\hline
\end{tabular}

a - mean \pm S.D.

*- Significant $\mathrm{p}$-value $(\mathrm{p}<0.05)$.

\begin{tabular}{|c|c|c|c|c|}
\hline & SCZ & BP & P Value \\
\hline \multicolumn{2}{|c|}{ PSLEa } & $99.93 \pm 28.627$ & $79.27 \pm 36.26$ & $0.017^{*}$ \\
\hline \multirow{3}{*}{ PSLE } & Mild & 0 & 1 & \multirow{3}{*}{0.052} \\
\hline & Moderate & 11 & 19 & \\
\hline & Severe & 19 & 10 & \\
\hline \multicolumn{2}{|c|}{ MSSIa $^{a}$} & $21.6 \pm 11.933$ & $17.33 \pm 11.427$ & 0.163 \\
\hline \multirow{3}{*}{ MSSI } & Low & 8 & 9 & \multirow{3}{*}{0.204} \\
\hline & $\begin{array}{c}\text { Mild- } \\
\text { Moderate }\end{array}$ & 4 & 9 & \\
\hline & Severe & 18 & 12 & \\
\hline \multicolumn{2}{|c|}{ BSIa } & $31.63 \pm 3.159^{b}$ & $28.13 \pm 6.707^{b}$ & 0.368 \\
\hline \multirow{3}{*}{ BSI } & & 0 & 0 & \multirow{3}{*}{0.608} \\
\hline & & 2 & 4 & \\
\hline & & 6 & 4 & \\
\hline
\end{tabular}

Table 2. Stressor, Suicidal Ideation, Intent and Diagnosis

amean \pm S.D.,

$\mathrm{b} N=8$.

$\mathrm{p}<0.05$ is taken as significant.

\begin{tabular}{|c|c|c|c|c|c|}
\hline & MSSI & Low & $\begin{array}{c}\text { Mild- } \\
\text { Moderate }\end{array}$ & Severe & P Value \\
\hline \multirow{2}{*}{ Gender } & Male & 3 & 2 & 7 & \multirow{2}{*}{0.220} \\
\hline & Female & 6 & 7 & 5 & \\
\hline \multicolumn{2}{|c|}{ Age ${ }^{a}$} & $\begin{array}{c}43.2 \pm \\
10.81\end{array}$ & $\begin{array}{l}39.2 \pm \\
11.42\end{array}$ & $\begin{array}{c}34.58 \pm \\
10.53\end{array}$ & 0.212 \\
\hline \multirow{3}{*}{ Religion } & Christian & 0 & 1 & 1 & \multirow{3}{*}{0.310} \\
\hline & Hindu & 8 & 4 & 9 & \\
\hline & Muslim & 1 & 4 & 2 & \\
\hline \multirow{5}{*}{ Education } & Illiterate & 3 & 3 & 1 & \multirow{5}{*}{$0.027^{*}$} \\
\hline & Primary & 1 & 1 & 1 & \\
\hline & Secondary & 4 & 3 & 5 & \\
\hline & $\begin{array}{c}\text { Higher } \\
\text { Secondary }\end{array}$ & 1 & 1 & 3 & \\
\hline & College & 0 & 1 & 2 & \\
\hline \multirow{5}{*}{$\begin{array}{l}\text { Marital } \\
\text { Status }\end{array}$} & Single & 2 & 1 & 4 & \multirow{5}{*}{0.814} \\
\hline & Married & 6 & 6 & 8 & \\
\hline & Separated & 0 & 1 & 0 & \\
\hline & Divorced & 1 & 1 & 0 & \\
\hline & Widowed & 0 & 0 & 0 & \\
\hline \multirow{2}{*}{$\begin{array}{l}\text { Type of } \\
\text { Family }\end{array}$} & Nuclear & 3 & 7 & 8 & \multirow{2}{*}{0.130} \\
\hline & Joint & 6 & 2 & 4 & \\
\hline \multicolumn{2}{|c|}{$\begin{array}{l}\text { Number of } \\
\text { Caregivers }^{\mathrm{a}}\end{array}$} & $\begin{array}{l}2.11 \pm \\
0.782\end{array}$ & $\begin{array}{l}1.44 \pm \\
0.726\end{array}$ & $\begin{array}{l}2.17 \pm \\
0.718\end{array}$ & 0.077 \\
\hline \multirow{3}{*}{\begin{tabular}{|c|} 
Socio- \\
economic \\
Status
\end{tabular}} & Low & 7 & 8 & 12 & \multirow{3}{*}{0.242} \\
\hline & Moderate & 2 & 1 & 0 & \\
\hline & High & 0 & 0 & 0 & \\
\hline \multirow[b]{2}{*}{ Locality } & Urban & 4 & 6 & 9 & \multirow{2}{*}{0.345} \\
\hline & Rural & 5 & 3 & 3 & \\
\hline
\end{tabular}

amean \pm S.D.,

$\mathrm{p}<0.05$ is taken as significant. 


\begin{tabular}{|c|c|c|c|c|c|}
\hline & MSSI & Low & \begin{tabular}{|c|} 
Mild- \\
Moderate
\end{tabular} & Severe & P Value \\
\hline \multicolumn{2}{|c|}{ Duration of Illness ${ }^{a}$} & $\begin{array}{c}14.88 \pm \\
10.21\end{array}$ & $13.38 \pm 8.49$ & $\begin{array}{c}8.73 \pm \\
7.29\end{array}$ & $0.007^{*}$ \\
\hline \multicolumn{2}{|c|}{ Years of Treatmenta } & $\begin{array}{c}12.52 \pm \\
9.58 \\
\end{array}$ & $9.92 \pm 8.69$ & $\begin{array}{c}6.64 \pm \\
6.48 \\
\end{array}$ & $0.008^{*}$ \\
\hline \multirow{2}{*}{$\begin{array}{l}\text { Interruption } \\
\text { of Treatment }\end{array}$} & Yes & 7 & 9 & 19 & \multirow{2}{*}{0.223} \\
\hline & No & 10 & 4 & 11 & \\
\hline \multirow{2}{*}{$\begin{array}{l}\text { Substance } \\
\text { Abuse }\end{array}$} & Yes & 7 & 4 & 13 & \multirow{2}{*}{0.737} \\
\hline & No & 10 & 9 & 17 & \\
\hline \multicolumn{6}{|c|}{ Table 4. MSSI and Overall IIlness Characteristics } \\
\hline
\end{tabular}

a is mean \pm S.D.

$\mathrm{p}<0.05$ is taken as significant

\begin{tabular}{|c|c|c|c|c|c|c|c|}
\hline \multicolumn{2}{|c|}{ Number of Attempts } & $\mathbf{0}$ & $\mathbf{1}$ & $\mathbf{2}$ & $\mathbf{3}$ & $\mathbf{4}$ & P Value \\
\hline \multirow{3}{*}{ MSSI } & Low & 14 & 3 & 0 & 0 & 0 & \\
\cline { 2 - 7 } & Mild-Moderate & 10 & 2 & 0 & 0 & 0 & \multirow{2}{*}{$0.000^{*}$} \\
\cline { 2 - 6 } & Severe & 8 & 11 & 9 & 1 & 1 & \\
\hline \multicolumn{7}{|c|}{ Table 5. MSSI and No. of Attempts } \\
\hline
\end{tabular}

$\mathrm{p}<0.05$ is taken as significant.

\section{DISCUSSION}

The study endeavoured to compare the characteristics of suicidal ideations and attempts in patients with schizophrenia and bipolar disorders. Socio-demographic factors, illness profile, the severity of the stressor temporal to the commencement of suicidal ideation and/or attempts, the suicidal intent, severity of suicidal ideation, severity of depression (if present) and severity of psychotic symptoms were the main factors that were scrutinised.

\section{Sociodemographic Characteristics}

Most of the pre-existing studies show that suicidal behaviour is prominent in the younger age group of psychiatric patients. These studies also emphasise that patients tend to be younger in the schizophrenia group in comparison with the bipolar disorder faction.(13-19) In this study, there was no major difference in the age distribution. A study by Dell'Osso(14) had reached to a similar conclusion. The difference in the composition of the Indian population must have resulted in such an inference.

There are mixed reports regarding the influence of gender on suicidality. Some studies show that females are more at risk.(14) There was no difference in the gender distribution in the study.

Hinduism is often associated with increased tolerance to suicide.(17) In this study, $75 \%$ of the study population was comprised of Hindus. This finding reflects the Indian population scenario, which is also comprised of $75 \%$ Hindus. But no significant association could be observed.

In previous comparative studies, it was found that patients with schizophrenia who had more years of education tend to have more suicidality. Studies on impact of education in bipolar disorder had come up with inconclusive result. When compared to people with bipolar disorder there were no illiterates in the schizophrenia group, which is in agreement with the previous studies. But on evaluating the association between education and suicidal ideation, a significant difference is seen in the bipolar disorder. Higher education was associated with increased severity of suicidal ideation. This discrepancy could be explained by the fact that mood disorders are more prevalent when compared to schizophrenia and must have resulted in such a finding.

A study by Agerbo et al(20) found that presence of a high paying job could increase the risk of suicide. But review studies support the view that unemployment is associated with increased suicidal risk.(18) In this study most of the patients were engaged in semi-skilled vocations. Grade of the job, income or duration of unemployment were not linked to increased suicidal behaviour in the study.

Social support refers to presence of a support system mainly provided by friends and family. Hor et al(4) in their meta-analysis concluded that there is no significant risk associated with lack of social support. A similar conclusion has been observed in this study. Koeda et al(13) in their comparison study emphasised on the risk associated with living alone. The study sample did not contain any patient who was living alone. This could have been the cause of such an interpretation.

\section{Illness Factors}

Duration of illness and treatment when evaluated in respect with suicidal ideation showed significant association. It was present for both the illness taken together. But when categorised, this association held true only in the bipolar disorder group. Longer duration of illness and treatment were associated with less severe suicidal ideation. In other words, suicidal ideations arise in the earlier phases of the course of illness, especially in bipolar disorder. This is in agreement with most of the previous studies. Regarding schizophrenia, a metaanalysis had failed to attain a significant correlation between duration of illness and suicidality.(18)

Regarding relation between suicidal intent and severity, in most of the studies the majority of the attempts are preceded by suicidal ideation. In agreement to the statement, this study also shows that all the suicidal attempters had suicidal ideation and all scored high in MSSI. Number of previous attempts has been postulated to be a major indicator for suicidal behaviour.(16)(21) The study is in tandem with the previous conclusions.

Depression can be manifested as part of schizophrenia or mood disorder. In this study, presence of depression was assessed in both groups. It was concluded from the analysis that depression was significantly associated with suicidal ideation in the whole sample as well as within the specific groups. This is in agreement of the previous studies.(15) Of the 30 cases in bipolar disorder, there was only one case of mania who harboured suicidal ideations during the episode. On MSSI, he scored only moderately severe suicidal ideation and he had not attempted.

Temporal stressors are long known to increase suicidal risk. When the total score was considered, there seemed to be a significant variance between the two groups with patients in schizophrenia showing a higher mean score on PSLES. This could reflect the poor problem-solving skills in schizophrenia leading to increased adverse situations in life. On conversion into severity grades, the difference became insignificant.

Risk of suicide due to psychotic symptoms have been evaluated, but with inconclusive results. T. Ishii et al(5) found the occurrence of hallucinations and delusions to be a proper risk factor. Here, in the study, the presence of delusions increases the suicidal ideations and hence corroborating with 
previous studies. There was no correlation with hallucinations though.

No association was found between substance use and suicidality. It could be due to more number of females in either group and they are less likely to use alcohol and other substances. Also, no association could be established between the use of alcohol at the time of attempt with the suicidal intent.

\section{Strength and Limitations}

The study is different from other studies, in that it included both patients with suicidal ideations and suicide attempts. Earlier studies had compared schizophrenia and overall mood disorders. This study was focused on comparing schizophrenia and bipolar affective disorder specifically. This study also attempted to explore the suicidality in manic patients.

The study was of a retrospective design. One of the major limitations of the study is the small sample size. The venture did not explore the study determinants in those who had completed suicide. Other determinants like premorbid personality and intelligence were not analysed.

\section{CONCLUSION}

The study showed that presence of stressors led to increased suicidality and hence treatment focusing on problem solving skills is highly recommended. Also, patients with bipolar disorder develop suicidal ideations earlier in the course. So bipolar patients should be followed up frequently at least during the early course of illness. This study warrants the need for a similar study with a larger sample size to obtain more conclusive results.

\section{REFERENCES}

[1] WHO| suicide. WHO 2015. Available from: http://www.who.int/mediacentre/factsheets/fs398/e n/.

[2] Benjamin SJ, Sadock VA, Ruiz P. Kaplan \& sadock's synopsis of psychiatry: behavioral sciences/clinical psychiatry. $11^{\text {th }}$ edn. Philadelphia: Wolters Kluwer 2015.

[3] Isometsä E. Suicidal behaviour in mood disorderswho, when, and why? Can J Psychiatry 2014;59(3):120-30.

[4] Hor K, Taylor M. Suicide and schizophrenia: a systematic review of rates and risk factors. J Psychopharmacol 2010;24(4 Suppl):81-90.

[5] Ishii T, Hashimoto E, Ukai W, et al. Characteristics of attempted suicide by patients with schizophrenia compared with those with mood disorders: a casecontrolled study in northern Japan. PLoS ONE 2014;9(5):e96272.

[6] Singh G, Kaur D, Kaur H. Presumptive stressful life events scale (psles) - a new stressful life events scale for use in India. Indian J Psychiatry 1984;26(2): 107-14.
[7] Joiner TE, Rudd MD, Rajab MH. The modified scale for suicidal ideation: factors of suicidality and their relation to clinical and diagnostic variables. J Abnorm Psychol 1997;106(2):260-5.

[8] Beck RW, Morris JB, Beck AT. Cross-validation of the suicidal intent scale. Psychol Rep 1974;34(2):445-6.

[9] Dingemans PM, Linszen DH, Lenior ME, et al. Component structure of the expanded brief psychiatric rating scale (BPRS-E). Psychopharmacology 1995;122(3):263-7.

[10] Addington J, Shah H, Liu L, et al. Reliability and validity of the calgary depression scale for schizophrenia (CDSS) in youth at clinical high risk for psychosis. Schizophr Res 2014;153(1-3):64-7.

[11] Trajković G, Starčević V, Latas M, et al. Reliability of the hamilton rating scale for depression: a metaanalysis over a period of 49 years. Psychiatry Research 2011;189(1):1-9.

[12] Altman EG, Hedeker DR, Janicak PG, et al. The clinician-administered rating scale for mania (CARSM): development, reliability, and validity. Biol Psychiatry 1994;36(2):124-34.

[13] Koeda A, Otsuka K, Nakamura H, et al. Characteristics of suicide attempts in patients diagnosed with schizophrenia in comparison with depression: a study of emergency room visit cases in Japan. Schizophrenia Research 2012;142(1-3):31-9.

[14] Dell'osso L, Casu G, Carlini M, et al. Sexual obsessions and suicidal behaviors in patients with mood disorders, panic disorder and schizophrenia. Ann Gen Psychiatry 2012;11(1):27.

[15] Shibre T, Hanlon C, Medhin G, et al. Suicide and suicide attempts in people with severe mental disorders in Butajira, Ethiopia: 10 year follow-up of a populationbased cohort. BMC Psychiatry 2014;14:150.

[16] Radomsky ED, Haas GL, Mann JJ, et al. Suicidal behavior in patients with schizophrenia and other psychotic disorders. Am J Psychiatry 1999;156:10.

[17] Kamal Z, Loewenthal KM. Suicide beliefs and behaviour among young muslims and hindus in the UK. Mental Health, Religion \& Culture 2002;5(2): 111-8.

[18] Hawton K, Sutton L, Haw C, et al. Schizophrenia and suicide: systematic review of risk factors. The British Journal of Psychiatry 2005;187(1):9-20.

[19] Ran MS, Wu QH, Conwell Y, et al. Suicidal behavior among inpatients with schizophrenia and mood disorders in Chengdu, China. Suicide Life Threat Behav 2004;34(3):311-9.

[20] Agerbo E. High income, employment, postgraduate education, and marriage: a suicidal cocktail among psychiatric patients. Arch Gen Psychiatry 2007;64(12):1377-84.

[21] Tidemalm D, Långström N, Lichtenstein P, et al. Risk of suicide after suicide attempt according to coexisting psychiatric disorder: Swedish cohort study with long term follow-up. BMJ 2008;337:a2205. 